\title{
PROJECT-BASED LEARNING APPROACH IN A CAD/CAM COURSE
}

\author{
El Ouafi, A; *Brousseau, J; **Ouellet, $\mathrm{H}$ \\ Département de mathématique, d'informatique et de génie \\ Université du Québec à Rimouski, Rimouski QC Canada \\ abderrazakelouafi@uqar.qc.ca,
}

\begin{abstract}
The tendency to promote the design component and to increase its influence in Canadian engineering programs is part of a general effort aiming at preparing the graduates for a better performance in the profession. It has led to program readjustments to support various design aspects in courses that not traditionally dedicated to design. The $\mathrm{CAD} / \mathrm{CAM}$ course offered by UQAR is an example of a course that exposes the students to the design process and allows student teams to convert a design into an operational prototype through the use of $\mathrm{CAD} / \mathrm{CAM}$ software, rapid prototyping, and $\mathrm{CNC}$ machining. This paper describes the context, the learning objectives and the educational model relating to this course.
\end{abstract}

\section{INTRODUCTION}

In engineering programs, the design courses that require the students to cover the product development process from the design concept to the prototype allow them to gain valuable experiences. Unfortunately, except for design courses that are scheduled at the end of their studies, and generally during the last year or last semester, this type of experience, although desirable and appreciated, is not systematically integrated in other courses. Small scale projects that focus on the basic concepts of design while favoring the integration of the contents and inserted into 2 nd or 3 rd year engineering courses will allow the students to experience and to combine professional practical experiences. The $\mathrm{CAD} / \mathrm{CAM}$ course offered in the mechanical and electromechanical engineering programs at UQAR is an example of a course that, while dedicated to $\mathrm{CAD} / \mathrm{CAM}$ tools, rapid prototyping and $\mathrm{CNC}$ machining learning, offers the students the possibility to convert their designs into fully operational prototypes.

\section{COURSE DESCRIPTION}

The CAD/CAM course covers subjects such as DFX approaches, $\mathrm{CAD} / \mathrm{CAM}$ tools, manufacturing process planning, CNC machining, rapid prototyping and assisted quality control. The course is given once a year during the winter session to approximately 12-16 students. The session is divided in two seven-week stages. During the first stage, the class regularly meets for nine hours a week during which the students are exposed to the various components of the course content through multimedia presentations and laboratory exercises (3 hours of course completed by practical work and assignments and 6 hours of laboratory exercises completed by a mini project for every laboratory exercise).

The second stage is reserved for a session project. Besides allowing the students to integrate, consolidate and to reinforce the CAD/CAM basics acquired during the first stage, the project is likewise used to introduce them to many product development concepts. They include the characterization of a problem to be solved, the wording of target goals, the production and the selection of the concept as well as the planning and the deployment of the resources required to realize them.

Therefore, for seven weeks, at the rate of nine hours per week, the students must exploit the competencies already developed in terms of teamwork, communications and creativity. They also have to make use of their experience in the handling of $\mathrm{CAD} / \mathrm{CAM}$ tools and the knowledge that they have acquired in their preceding courses (materials, strength of materials, manufacturing processes, quality assurance, etc.). The intention is to bring students to design and manufacture products that meet specific needs.

\section{PROJECT DESCRIPTION}

The projects can be proposed by businesses, by the teaching staff or by the students themselves. Each team of 2 to 4 students must develop its project while respecting a timetable adjusted to the scale and the complexity of the project and articulated around the following six steps:

1. Problem identification, needs analysis, and objectives formulation.

2. Information gathering and specifications definition.

3. Conceptualization (concepts generation to address the problem definition and selection of a preferred concept).
4. Detailed design (apply engineering rules and analysis to develop an optimal design).

5. Manufacturing planning (CAM tools and $\mathrm{CNC}$ programming).

6. Manufacturing and assembly (rapid prototyping, CNC machining and prototype building).

7. Implementation, testing and validation.

All projects must respect the following basic rules: (i) each of the six steps must not last more than a week, (ii) a minimum of $75 \%$ of the parts must be made on CNC machines (VMC Bridgeport TC1 and Mazak Integrex 100-ST), and (iii) materials must be selected from the catalog of the often used materials in the laboratory. The obligatory deliverables required from each team are: virtual prototype, detail and assembly drawings, manufacturing planning portfolio and operational prototype.

Globally, the competencies acquired during the course were applied to the projects and succeeded in inspiring the design and the manufacture of several useful products. Figure 1 shows some examples of student's achievement in this course.
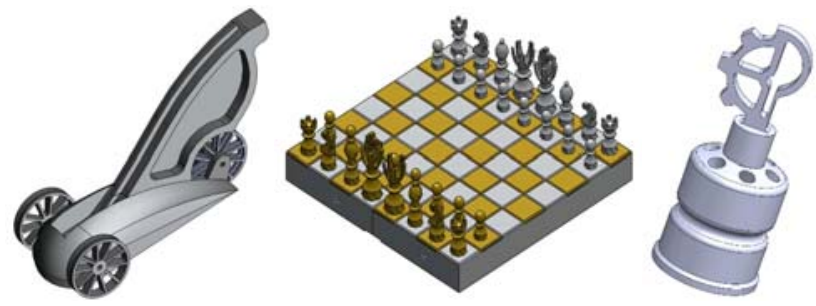

Figure 1: Samples of student's achievement

This is just the second year that this course is offered in this format. Although the benefits of this format are numerous and obvious, the preliminary assessment do not clearly establish the real impact of the course on the development of design skills. However, it is clear that students enjoy the pedagogical model and believe that this is an effective approach to learn and practice $\mathrm{CAD} / \mathrm{CAM}$ tools.

\section{CONCLUSION}

The two-year experience conducted by UQAR shows that the introduction of the project-based learning approach in the CAD/CAM course has proven to be effective not only for the reinforcement of theoretical learning and practices covered in the course but also because it consolidates learning and concepts covered by other courses. Several professors indicated that the students consulted them to obtain details or precisions on aspects related to their projects. Moreover, considering the nature of the projects, the students could make an evaluation of the difficulty of producing an operational prototype. In fact, the CAD/CAM tools offer the possibility to simulate various constraints design and manufacturing, however only the physical prototyping can effectively allow the students to observe and identify in a concrete way the attributes of a good design.

\section{REFERENCES}

1. CEAB: Canadian Engineering Accreditation Board, Accreditation criteria and procedures, 2009.

2. Dym CL, Little P, Engineering Design, A project-based introduction, John Wiley and Sons, 2000.

3. Dutson J, Todd RH, Magleby S.P, Sorensen C.D, A review of literature on teaching engineering design through project-oriented capstone courses, Journal of Engineering Education, Vol. 86, 1997.

4. Bordogna J, Fromm E, Ernst EW, Engineering education: Innovation through integration, Journal of Engineering Education, Vol. 82, 1993.

\section{AFFILIATED INSTITUTIONS FOR CO-AUTHORS}

* Département de mathématique, d'informatique et de génie, Université du Québec à Rimouski, Rimouski, Canada.Jean_Brousseau@uqar.qc.ca ** Département génie mécanique, Cégep de Rimouski, Rimouski,

Canada.Henri.Ouellet@cegep-rimouski.qc.ca 